\title{
The effect of L-glutamine and trehalose on dog sperm cryopreservation
}

\author{
Caner Öztürk ${ }^{1}$, Neșe Hayat Aksoy² \\ Aksaray University, Faculty of Veterinary Medicine, ${ }^{1}$ Department of Reproduction and Artificial Insemination, \\ ${ }^{2}$ Department of Biochemistry, Aksaray, Turkey \\ Received December 15, 2020 \\ Accepted May 26, 2021
}

\begin{abstract}
This study aimed to test different doses of L-glutamine and trehalose in the canine semen diluent while determining their protective effects on spermatological and biochemical indices of the thawed samples. Semen samples were collected from three fertile dogs using the digital manipulation method. The mixed ejaculates were divided into five portions at $37^{\circ} \mathrm{C}$ and diluted with additives. Five study groups were formed with L-glutamine (10 and $20 \mathrm{mM})$, trehalose (25 and $50 \mathrm{mM}$ ), and no additives (control). After the dilution, the semen samples were cooled for $1.5 \mathrm{~h}$ at $5{ }^{\circ} \mathrm{C}$ and frozen $\left(-110\right.$ to $\left.-120^{\circ} \mathrm{C}\right)$ in liquid nitrogen vapor. Then, they were stored at $-196{ }^{\circ} \mathrm{C}$. For spermatological evaluations, samples were thawed at $38{ }^{\circ} \mathrm{C}$ for $30 \mathrm{~s}$. L-glutamine $(20 \mathrm{mM})$ was found to be significantly different $(P<0.05)$ and led to higher percentages of motility, membrane integrity, and acrosome integrity compared to the control group. Considering the total oxidant status (TOS) assay, the lower values were determined in all the antioxidant groups compared to the control group $(P<0.05)$. Supplementing the semen extender with L-glutamine showed a higher total antioxidant status (TAS) concentration compared to the control group $(P<0.05)$. As a result of this study, a higher protective effect was found in all the spermatological evaluations after thawing the frozen semen samples, especially in the group containing L-glutamine $(20 \mathrm{mM})$.
\end{abstract}

Acrosome integrity, membrane integrity, TAS, TOS

Dog breeders have shown increasing interest in reproductive biotechnology, but the assisted breeding techniques for dogs are limited to artificial insemination and semen protection (Gobello and Corrada 2003). Sperm cryopreservation decreases sperm motility and fertility by causing the formation of reactive oxygen species (ROS). However, identifying the important stages in this process has contributed to the prevention of oxidative stress (Lucio et al. 2016a). Lipid peroxidation (LPO) in the freeze-thawed semen samples caused higher concentrations of intracellular hydrogen peroxide along with DNA fragmentation compared to fresh semen in dogs (Kim et al. 2010). Many researchers have focused on using antioxidants as preservatives to reduce the negative effects of ROS on sperm cells (Neagu et al. 2010; Lucio et al. 2016b).

The cytoplasm of mammalian sperm cells decreased during the maturation phase of spermatogenesis. Due to the predominantly cytoplasmic nature of the antioxidant defense systems, the cells that are deprived of antioxidant reserves are vulnerable to the harmful effects of lipid peroxidation during cryopreservation (Iqbal et al. 2016). Hence, to reduce the negative effects of oxidative stress on semen and to protect the spermatological indices, many studies have documented that adding antioxidants to the extender could be beneficial in preserving the sperm indices after thawing in animals such as rams (Gungor et al. 2018), bulls (Büyükleblebici et al. 2014), and canines (Caturla-Sánchez et al. 2018).

Trehalose, a disaccharide sugar, has antioxidative properties at low doses, and when used in the diluent, it could protect spermatozoa during cryopreservation by reducing the LPO (Büyükleblebici et al. 2014). Trehalose protected the sperm cells from osmotic stress caused by the freezing process. Also, its cryoprotective effect is attributed to the increased sperm membrane fluidity before the freezing process occurs (Aboagla and Terada 2003;

Address for correspondence:

Dr.Caner Öztürk

Department of Reproduction and Artificial Insemination

Faculty of Veterinary Medicine

Aksaray University, Aksaray, Turkey 
Zhang et al. 2016). The post-thaw semen analysis determined that trehalose preserved motility, vitality, and membrane integrity in different species while also reducing oxidative stress (Iqbal et al. 2016; Park et al. 2018; Keskin et al. 2020).

Glutamine has an alpha-amino acid structure and is one of the components of glutathione, which has a significant role in protecting the sperm cells against ROS (Topraggaleh et al. 2014). It is also a major free amino acid found in mammalian semen, mainly in seminal plasma (Setchell et al. 1967). Organisms are known to utilize amino acids to resist cold shock. For example, in the ram, glutamine acted at the extracellular level after the dissolution to improve the semen motility and oxidative stress indocators (Bucak et al. 2009). The addition of glutamine to semen was reported to be beneficial towards the motility and oxidative stress indicators in boar sperm during short-term storage (Wang et al. 2018) and ram semen after the thawing of the frozen sample (Bucak et al. 2009).

This study aimed to test different doses of L-glutamine and trehalose in the canine semen diluent while determining their protective effects on spermatological and biochemical indices of the thawed samples.

\section{Materials and Methods}

Chemicals

The chemicals used in the study were procured from Sigma-Aldrich Chemical (St Louis, MO, USA).

Experimental design

Three adult fertile dogs were used in this study. The animals were provided by a private breeder under the guidance of the dog protection association. The Ethics Committee permission was obtained as well (Ethics Committee of Mehmet Akif Ersoy University, No 2016/217).

Collection and preparation of semen

The study was continued for four weeks and one ejaculate per week was collected. From the collected semen, the ones with more than $75 \%$ motility and a concentration of $200 \times 10^{6}$ spermatozoa $/ \mathrm{ml}$ were used. The tris base extender (TBE) was used to dilute the semen (tris $297.58 \mathrm{mM}$, citric acid $96.32 \mathrm{mM}$, fructose $82.66 \mathrm{mM}, 20 \%$ egg yolk, $6 \%$ glycerol). The five groups formed based on the additives were as follows:

TBE + L-glutamine $10 \mathrm{mM}$

$\mathrm{TBE}+$ L-glutamine $20 \mathrm{mM}$

$\mathrm{TBE}+$ trehalose $\quad 25 \mathrm{mM}$

$\mathrm{TBE}+$ trehalose $\quad 50 \mathrm{mM}$

No additives (control)

The samples were loaded onto $0.25 \mathrm{ml}$ straws and equilibrated for $1.5 \mathrm{~h}$ at $5{ }^{\circ} \mathrm{C}$. The loaded straws were frozen in liquid nitrogen vapor $(15 \mathrm{~min})$ and stored in liquid nitrogen $\left(-196^{\circ} \mathrm{C}\right)$. After $48 \mathrm{~h}$ of freezing, the straws were thawed in a water bath for $30 \mathrm{~s}$ at $38^{\circ} \mathrm{C}$ for spermatological and biochemical evaluations.

\section{Sperm motility}

The motility of spermatozoa was determined using a phase-contrast microscope. For the subjective evaluation, at least five microscopic areas were scanned at $\times 400$ magnification, and the mean score was determined.

Plasma membrane integrity

Semen samples were diluted with the tris stock solution at a ratio of 1:3 using a modified staining protocol of Garner and Johnson (1995). Thirty $\mu$ l of the diluted sample were mixed with $6 \mu$ l of SYBR-14 and $2.5 \mu 1$ of propidium iodide (PI) and then incubated at $37^{\circ} \mathrm{C}$ in the dark for $20 \mathrm{~min}$. The process was completed by adding $10 \mu \mathrm{l}$ of Hancock solution.

\section{Acrosome integrity}

The method by Nagy et al. (2003) was used to determine the integrity of the acrosome. The semen was diluted with the tris diluent at a ratio of $1: 3$. Then, $60 \mu$ of semen were mixed with $10 \mu 1$ of FITC-PNA and $2.5 \mu 1$ of PI and incubated at $37^{\circ} \mathrm{C}$ in the dark for $20 \mathrm{~min}$. The process was completed by adding $10 \mu 1$ of Hancock solution (Schafer and Holzmann 2000).

\section{Semen preparation for enzymatic assays}

To separate the spermatozoa, the ejaculate was centrifuged at $800 \mathrm{~g}$ for $15 \mathrm{~min}$ at $4{ }^{\circ} \mathrm{C}$ and then washed thrice with phosphate buffered saline (PBS: $\mathrm{pH}$ 7.2-7.6; P4417). After the last centrifugation, $0.5 \mathrm{ml}$ of PBS was added 
to the suspension. For homogenization, the sperm suspension was placed in a $2 \mathrm{ml}$ ice water chamber and then subjected to 8 repetitions of sonication for $4 \mathrm{~s}$ each.

Analysis of the total antioxidant status of semen

The antioxidative status (TAS) of sperm samples was determined using the method developed by Erel (2004). It is important to perform these tests in various biological fluids with high reliability and speed. In this method, the colour of the sample changes into a dark blue-green colour, which is measured as the absorbance change. The calibration analysis at $660 \mathrm{~nm}$ was performed with a stable antioxidant standard solution.

Analysis of the total oxidant status of semen

The total oxidant levels (TOS) of semen samples were determined by the measurement method specified by Erel (2005). The oxidants present in the samples at acidic conditions could oxidize the ferrous ion-chelator complex to ferric ion. The colour intensity determined using the spectrophotometric method was proportional to the total amount of oxidant molecules in the sample. Test results were expressed as $\mu \mathrm{mol}_{2} \mathrm{O}_{2}$ equivalent per litre at $530 \mathrm{~nm}$.

\section{Statistical analysis}

Normality and homogeneity of variances were verified using Shapiro-Wilk test. The results of thawed sperm samples were expressed as mean \pm standard deviation by one-way analysis of variance (ANOVA). Duncan's post hoc test was used to determine the differences between the groups. Differences with the values of $P<0.05$ were considered significant. Analyses were made using the SPSS 21 program.

\section{Results}

As shown in Table 1, the diluent group that contained $20 \mathrm{mM}$ glutamine showed a higher protective effect on the membrane integrity, motility, and acrosome integrity of the sperms compared to the control group $(P<0.05)$. The highest TAS concentrations were reached in the $20 \mathrm{mM}$ glutamine group, which showed a significant difference compared to the control group. The highest TOS value was reached in the control group, which showed a significant difference compared to all the other groups. We found the $50 \mathrm{mM}$ trehalose group to be useful in the TOS value (Table 2) and it showed a significant difference compared to the control group $(P<0.05)$.

Table 1 . The values (mean $\pm \mathrm{SD}$ ) of the membrane integrity (\%), motility (\%), and acrosome integrity (\%) in the frozen-thawed dog semen samples.

\begin{tabular}{lccc}
\hline Groups & Membrane integrity & Motility & Acrosome integrity \\
\hline L-glutamine $10 \mathrm{mM}$ & $56.22 \pm 5.84^{\mathrm{ab}}$ & $52.50 \pm 5.00^{\mathrm{a}}$ & $61.35 \pm 2.76^{\mathrm{a}}$ \\
L-glutamine $20 \mathrm{mM}$ & $61.80 \pm 5.31^{\mathrm{a}}$ & $56.25 \pm 2.50^{\mathrm{a}}$ & $62.00 \pm 4.78^{\mathrm{a}}$ \\
Trehalose $25 \mathrm{mM}$ & $54.78 \pm 6.11^{\mathrm{ab}}$ & $48.75 \pm 6.29^{\mathrm{ab}}$ & $55.68 \pm 1.87^{\mathrm{b}}$ \\
Trehalose $50 \mathrm{mM}$ & $59.08 \pm 4.12^{\mathrm{ab}}$ & $55.00 \pm 4.08^{\mathrm{a}}$ & $60.88 \pm 3.78^{\mathrm{a}}$ \\
Control & $50.68 \pm 4.29^{\mathrm{b}}$ & $43.75 \pm 4.79^{\mathrm{b}}$ & $53.00 \pm 3.53^{\mathrm{b}}$ \\
\hline
\end{tabular}

a,b values with different superscripts within columns are significantly different $(P<0.05)$

Table 2. The values (mean \pm SD) of total oxidant status (TOS), and total antioxidant status (TAS) in the frozen-thawed dog semen samples.

\begin{tabular}{lcr}
\hline Groups & TAS $(\mathrm{mmol} / \mathrm{l})$ & TOS $(\mu \mathrm{mol} / \mathrm{l})$ \\
\hline L-glutamine $10 \mathrm{mM}$ & $0.30 \pm 1.71^{\mathrm{b}}$ & $5.2 \pm 1.31^{\mathrm{b}}$ \\
L-glutamine $20 \mathrm{mM}$ & $0.60 \pm 2.16^{\mathrm{a}}$ & $3.76 \pm 0.90^{\mathrm{b}}$ \\
Trehalose $25 \mathrm{mM}$ & $0.36 \pm 1.63^{\mathrm{b}}$ & $5.18 \pm 1.52^{\mathrm{b}}$ \\
Trehalose $50 \mathrm{mM}$ & $0.43 \pm 2.78^{\mathrm{ab}}$ & $3.23 \pm 1.29^{\mathrm{b}}$ \\
Control & $0.25 \pm 2.86^{\mathrm{b}}$ & $12.29 \pm 2.87^{\mathrm{a}}$ \\
\hline
\end{tabular}

${ }^{\mathrm{a}, \mathrm{b}}$ values with different superscripts within columns are significantly different $(P<0.05)$ 


\section{Discussion}

Commercial diluents have been developed for domesticated animal species and are used in most production stations as standard diluents. However, such comprehensive field fertility results are not available for dogs. Also, only a little incentive was available to develop standardized semen extenders (Farstad 2009). Although successful results were obtained in sperm cryopreservation, the routine procedure caused serious harmful effects on sperm functions. On the other hand, the additives with antioxidant properties were reported to reduce the effect of ROS and cold shock damages (Amidi et al. 2016).

This study was aimed to determine the effects of antioxidant application on the spermatological indices and oxidative stress while defining a useful diluent for dog sperms. The sperm motility, membrane integrity, acrosome integrity, TAS, and TOS levels were examined after thawing the frozen semen samples. Glycerol and glutamine were used in the semen extender to provide a synergistic cryoprotective role during cryopreservation (Khlifaoui et al. 2005). The testicular damage caused by the chemicals could be prevented by oral glutamine consumption due to its free radical neutralizing properties (Chinoy and Mehta 1999). Many researchers have stated that glutamine is beneficial for the motility of post-thawed sperm, its acrosome, and membrane integrity (Renard et al. 1996; Amirat-Briand et al. 2009; Bucak et al. 2009). Despite similar results, Bucak et al. (2009) reported that glutamine (2.5 and $5 \mathrm{mM}$ ) could not provide a preventive effect on the oxidative stress in ram semen, which could be attributed to the fact that glutamine has a toxic effect at a concentration above $20 \mathrm{mM}$ (Wang et al. 2018). Glutamine is biphasic and could not demonstrate sufficient protection at the doses of $5 \mathrm{mM}$ or less. Similarly, our study also showed that $20 \mathrm{mM}$ glutamine had a positive effect on sperm quality compared to the $10 \mathrm{mM}$ glutamine group, which indicates that TAS and TOS levels are important factors too in affecting the quality of the dog sperm after being thawed. The motility and the membrane and acrosome integrity results obtained in our study support this effect. Our results were also in line with the studies conducted by other researchers on the semen of bulls (Dawra et al. 2015) and stallions (Khlifaoui et al. 2005).

Trehalose showed its cryoprotective effect by interacting with the membrane phospholipids to provide stability or by binding to extracellular ice crystals, which was similar to the action of glycerol (Bakas and Disalvo 1991; Gao and Critser 2000). Trehalose is stated to have antioxidant properties to protect the sperm cells from ROS damage (Tuncer et al. 2013). In our study, the addition of trehalose to the canine semen decreased the TOS production after the thawing of the frozen sample. These results were consistent with studies conducted on rabbits (Zhu et al. 2017) and Karan Fries (Chhillar et al. 2012) as well. Plasma membrane integrity and acrosome integrity is important in the evaluation of semen quality (Garner and Johns on 1995). We obtained higher values of motility, membrane integrity, and acrosome integrity in the $50 \mathrm{mM}$ trehalose group compared to the $25 \mathrm{mM}$ trehalose and the control groups, which was consistent with the study on buffaloes by Kumar and Atreja (2012) and Reddy et al. (2010) who showed the benefit of using higher amounts of trehalose. During the cryopreservation, oxidative stress, osmotic stress, or ice crystal formation caused acrosome damage in the cells (Holt 2000). The use of trehalose in the semen extender provided a protective effect on the acrosome integrity of the semen of rams (Bucak et al. 2007) and goats (Quan et al. 2012). Aisen et al. (2005) stated that trehalose added to the diluent preserved the integrity of sperm plasma and acrosomal membranes. This contributed to the organelle protection during the freezing process by intracellular dehydration due to hypertonicity of the diluents and reduced formation of ice crystals. Similar to the above-mentioned studies, our study also showed the cryoprotective effects of trehalose on semen samples. 
In conclusion, L-glutamine $(20 \mathrm{mM})$ used in the canine semen extender showed a protective effect on the evaluations of motility, membrane and acrosome integrity after the thawing process. A similar protective effect was achieved in the group with corresponding TAS and TOS measurements. However, upon the usage of low doses of the antioxidants in our study, the protective effect was not observed at the desired level.

\section{References}

Aboagla EME, Terada T 2003: Trehalose-enhanced fluidity of the goat sperm membrane and its protection during freezing. Biol Reprod 69: 1245-1250

Aisen E, Quintana M, Medina V, Morello H, Venturino A 2005: Ultramicroscopic and biochemical changes in ram spermatozoa cryopreserved with trehalose-based hypertonic extenders. Cryobiology 50: 239-249

Amidi F, Pazhohan A, Nashtaei MS, Khodarahmian M, Nekoonam S 2016: The role of antioxidants in sperm freezing: a review. Cell Tissue Bank 17: 745-756

Amirat-Briand L, Bencharif D, Vera-Munoz O, Ali HBH, Destrumelle S, Desherces S, Schmidt E, Anton M, Tainturier D 2009: Effect of glutamine on post-thaw motility of bull spermatozoa after association with LDL (low density lipoproteins) extender: preliminary results. Theriogenology 71: 1209-1214

Bakas LS, Disalvo EA 1991: Effect of $\mathrm{Ca}^{2+}$ on the cryoprotective action of trehalose. Cryobiology 28: 347-353

Bucak MN, Ateşşahin A, Varışlı Ö, Yüce A, Tekin N, Akçay A 2007: The influence of trehalose, taurine, cysteamine and hyaluronan on ram semen: microscopic and oxidative stress parameters after freeze-thawing process. Theriogenology 67: 1060-1067

Bucak MN, Tuncer PB, Sarı̈zkan S, Ulutaş PA 2009: Comparison of the effects of glutamine and an amino acid solution on post-thawed ram sperm parameters, lipid peroxidation and anti-oxidant activities. Small Rumin Res 81: 13-17

Büyükleblebici S, Tuncer PB, Bucak MN, Eken A, Sarı̈zkan S, Taşdemir U, Endirlik BÜ 2014: Cryopreservation of bull sperm: Effects of extender supplemented with different cryoprotectants and antioxidants on sperm motility, antioxidant capacity and fertility results. Anim Reprod Sci 150: 77-83

Caturla-Sánchez E, Sánchez-Calabuig MJ, Pérez-Gutiérrez JF, Cerdeira J, Castaño C, Santiago-Moreno J 2018: Vitrification of dog spermatozoa: Effects of two cryoprotectants (sucrose or trehalose) and two warming procedures. Cryobiology 80: 126-129

Chhillar S, Singh VK, Kumar R, Atreja SK 2012: Effects of Taurine or Trehalose supplementation on functional competence of cryopreserved Karan Fries semen. Anim Reprod Sci 135: 1-7

Chinoy NJ, Mehta D 1999: Beneficial effects of the amino acids glycine and glutamine on testis of mice treated with sodium fluoride. Fluoride 32: 162-170

Dawra V, Yadav B, Yadav S 2015: Effect of glutamine supplementation and replacement of tris-egg yolk based extender with defatted cow milk on spermatozoa quality after equilibration and thawing. Vet World 8: 1027-1031

Erel O 2004: A novel automated method to measure total antioxidant response against potent free radical reactions. Clin Biochem 37: 112-119

Erel O 2005: A new automated colorimetric method for measuring total oxidant status. Clin Biochem 38: 1103-1111

Farstad W 2009: Cryopreservation of canine semen-new challenges. Reprod Domest Anim 44: 336-341

Gao D, Critser JK 2000: Mechanisms of cryoinjury in living cells. Ilar J 41: 187-196

Garner DL, Johnson LA 1995: Viability assessment of mammalian sperm using SYBR-14 and propidium iodide, Biol Reprod 53: 276-284

Gobello C, Corrada YA 2003: Biotechnology in canine reproduction: an update. Analecta vet 23: 30-37

Gungor S, Ata A, Inanc ME 2018: Effects of trehalose and catalase on the viability and kinetic parameters of cryopreserved ram sperm. Acta Sci Vet 46: 1577

Holt WV 2000: Basic aspects of frozen storage of semen. Anim Reprod Sci 62: 3-22

Iqbal S, Andrabi SMH, Riaz A, Durrani AZ, Ahmad N 2016: Trehalose improves semen antioxidant enzymes activity, post-thaw quality, and fertility in Nili Ravi buffaloes (Bubalus bubalis). Theriogenology 85: 954-959

Keskin N, Erdogan C, Bucak MN, Ozturk AE, Bodu M, Ili P, Baspinar N, Dursun S 2020: Cryopreservation effects on ram sperm ultrastructure. Biopreserv Biobank 18: 441-448

Khlifaoui M, Battut I, Bruyas JF, Chatagnon G, Trimeche A, Tainturier D 2005: Effects of glutamine on post-thaw motility of stallion spermatozoa: an approach of the mechanism of action at spermatozoa level. Theriogenology 63: $138-149$

Kim SH, Yu DH, Kim YJ 2010: Effects of cryopreservation on phosphatidylserine translocation, intracellular hydrogen peroxide, and DNA integrity in canine sperm. Theriogenology 73: 282-292

Kumar R, Atreja SK 2012: Effect of incorporation of additives in tris-based egg yolk extender on buffalo (Bubalus bubalis) sperm tyrosine phosphorylation during cryopreservation. Reprod Domest Anim 47: 485-490

Lucio CF, Regazzi FM, Silva LCG, Angrimani DSR, Nichi M, Vannucchi CI 2016a: Oxidative stress at different stages of two-step semen cryopreservation procedures in dogs. Theriogenology 85: 1568-1575

Lucio C, Silva LCG, Regazzi FM, Angrimani DSR, Nichi M, Assumpção MEO, Vannucchi CI 2016b: Effect of reduced glutathione (GSH) in canine sperm cryopreservation: In vitro and in vivo evaluation. Cryobiology $\mathbf{7 2}$ : $135-140$ 
Nagy S, Jansen J, Topper EK, Gadella BM 2003: A triple-stain flow cytometric method to assess plasma and acrosome membrane integrity of cryopreserved bovine sperm immediately after thawing in presence of egg-yolk particles. Biol Reprod 68: 1828-1835

Neagu VR, García BM, Sandoval CS, Rodríguez AM, Ferrusola CO, Fernández LG, Tapia JA, Peña FJ 2010: Freezing dog semen in presence of the antioxidant butylated hydroxytoluene improves post thaw sperm membrane integrity. Theriogenology 73: 645-650

Park KS, Chun JL, Kim EY, Lee JH, Lee HS, Yamauchi N, Kyungbon L, Kim MK 2018: Protective effect of trehalose on canine spermatozoa in cryopreservation. J Fac Agric Kyushu Univ 63: 53-60

Quan GB, Hong QH, Lan ZG, Yang HY, Wu SS 2012: Comparison of the effect of various disaccharides on frozen goat spermatozoa. Biopreserv Biobank 10: 439-445

Reddy NSS, Mohanarao GJ, Atreja SK 2010: Effects of adding taurine and trehalose to a tris-based egg yolk extender on buffalo (Bubalus bubalis) sperm quality following cryopreservation. Anim Reprod Sci 119: 183-190

Renard P, Grizard G, Griveau JF, Sion B, Boucher D, Le Lannou D 1996: Improvement of motility and fertilization potential of post thaw human sperm using glutamine. Cryobiology 33: 311-319

Schafer S, Holzmann A 2000: The use of transmigration and spermac stain to evaluate epididymal cat spermatozoa. Anim Reprod Sci 59: 201-211

Setchell BP, Hinks NT, Voglmayr JK, Scott TW 1967: Amino acids in ram testicular fluid and semen and their metabolism by spermatozoa. Biochem J 105: 1061-1065

Topraggaleh TR, Shahverdi A, Rastegarnia A, Ebrahimi B, Shafiepour V, Sharbatoghli M, Esmaeili V, Janzamin E 2014: Effect of cysteine and glutamine added to extender on post-thaw sperm functional parameters of buffalo bull. Andrologia 46: 777-783

Tuncer PB, Taşdemir U, Büyükleblebici S, Özgürtaş T, Coşkun E, Erol H, Aydin FN, Gürcan İS 2013: Effects of different doses of trehalose supplementation in egg yolk extender in frozen-thawed Angora buck semen. Small Rumin Res 113: 383-389

Wang S, Sun M, Wang N, Yang K, Guo H, Wang J, Zhang Y, Yue S, Zhou J 2018: Effects of L-glutamine on boar sperm quality during liquid storage at $17^{\circ} \mathrm{C}$. Anim Reprod Sci 191: 76-84

Zhang M, Oldenhof H, Sieme H, Wolkers WF 2016: Freezing-induced uptake of trehalose into mammalian cells facilitates cryopreservation. Biochim Biophys Acta 1858: 1400-1409

Zhu Z, Fan X, Pan Y, Lu Y, Zeng W 2017: Trehalose improves rabbit sperm quality during cryopreservation. Cryobiology 75: 45-51 